Original Article

\title{
OBLIGATORY ALTERATIONS IN THE MORPHOLOGY OF MEDIAN NERVE: A SONOGRAPHIC STUDY IN ASYMPTOMATIC INDIVIDUALS
}

\author{
Vandana Lakra, Garima Sehgal, Jyoti Chopra, Anita Rani, Kaweri Dande \\ Department of Anatomy, King George's Medical University, Lucknow, UP, India
}

\begin{abstract}
Introduction: Median nerve is formed in axilla by contributions from medial and lateral cords of brachial plexus. It descends in the arm, forearm and then through carpal tunnel in close conjunction with flexor tendons of forearm. Carpal tunnel syndrome (CTS) is a common entrapment neuropathy. Median nerve cross sectional area (CSA) and ratio of nerve major axis to minor axis (flattening ratio) serve as potential diagnostic criteria for carpal tunnel syndrome. Median nerve cross sectional area and flattening ratio (FR) can be assessed by ultrasonography (US).
\end{abstract}

Aim of the study was to assess median nerve by US and tabulate mean values for CSA and FR in asymptomatic population. This would serve to limit the cut-off values that differentiate asymptomatic nerves from neuropathic nerves.

Material \& Methods: Study was conducted in the Department of Anatomy, KGMU, Lucknow. Fifty randomly selected asymptomatic volunteers (undergraduate students: 30 males, 20 females) participated in the study. Sonography was performed to evaluate certain morphological dimensions of median nerve. Height, weight and wrist circumference of participants were also noted. Ultrasonography was performed using high frequency linear probe and observations were made at two pre-determined sites. Observations were recorded, tabulated and analyzed.

Results: Median nerve was easily observable at both sites. It was round in shape in forearm (Fo), and flattened as it reached the carpal tunnel (Ct). Among all 50 study subjects, at both sites, flattening was more on right side (FRFoRt-1.71; FRCtRt-3.08) than on left side (FRFoLt-1.66; FRCtLt-2.78). In right forearm, nerve was flatter in females (FRFoRt-1.77) as compared to males (FRFoRt-1.68). In left forearm, median nerve was slightly rounder in females (FRFoLt-1.65) as compared to males (FRFoLt-1.67). At the distal wrist crease on right side, increased flattening was observed in females (FRCtRt-3.30) as compared to males (FRCtRt-2.94), whereas on left side, at same site flattening was more in females (males FRCtLt-2.74; females FRCtLt-2.83).

Conclusion: Altered FR has both diagnostic as well as prognostic values in carpal tunnel syndrome. The database generated from the study will help in facilitating comparisons between normal, asymptomatic and pathological, asymptomatic individuals.

Keywords: Median nerve, ultrasound, carpal tunnel syndrome, cross sectional area, flattening ratio.

\section{INTRODUCTION}

Median nerve is an important nerve of upper limb. It is a mixed nerve, formed in axilla by contributions from medial and lateral cords of brachial plexus. The nerve descends in axilla in close proximity to third part of axillary artery, in the arm it crosses in front of brachial artery from lateral to medial side close to insertion of coracobrachialis, and then, descends to lie between 
brachialis and bicipital aponeurosis in the cubital fossa, it enters the forearm between two heads of pronator teres, and descends in forearm between flexor digitorum superficialis (FDS) and flexor digitorum profundus (FDP). Proximal to flexor retinaculum median nerve curves around the tendon of FDS and becomes superficial, lying between flexor carpi ulnaris (FCR) and palmaris longus (PL). The nerve courses through the carpal tunnel along with tendons of long flexors of the fingers and finally splits into digital branches and muscular branches [1]. The digital branches supply the skin of thumb, index, middle, and the radial side of ring finger, while the muscular branches supply thenar muscles and some lumbricals [2]. The nerve is nearly circular on crosssection in arm, but, as it courses along cubital fossa, forearm and carpal tunnel it undergoes alteration in shape [3]. To investigate this alteration, median nerve was assessed by high-resolution ultrasonography (HRUS). HRUS has become the principle diagnostic tool for evaluating peripheral neuropathies; it can assess all main peripheral nerves of upper limb [4]. Ultrasonography can assess median nerve crosssectional area (CSA) and flattening ratio (FR) at forearm as well as carpal tunnel. Cross-sectional area of nerve decreases as the nerve courses distally, except at cubital fossa and distal wrist crease where it shows an abrupt increase. The Flattening ratio is defined as ratio of nerve's transverse axis to that of anteroposterior axis. This ratio serves as a biomarker and a potential diagnostic criterion for CTS [5]. In humans, carpal tunnel syndrome is the most common nerve entrapment. Ultrasound imaging technique is an addendum to electrodiagnostic tests for diagnosing CTS. CTS is accompanied by increase in median nerve CSA just proximal to tunnel and increased flattening in the distal tunnel.

Hence, median nerve CSA and shape changes along its course. Among different population groups the change may differ quantitatively; there is also a comparable difference in the change that is physiological from the change which is part of a pathology.

The study was planned to assess median nerve morphology by ultrasonography, and tabulate the mean values for CSA, FR and wrist-to-forearm ratio (WFR) in an asymptomatic population. The morphological assessment would help to limit cut-off values that differentiate asymptomatic nerves from neuropathic nerves.

\section{MATERIAL AND METHODS}

This descriptive, cross-sectional study was carried out in the Ultrasound laboratory of Department of Anatomy, King George's Medical University, Lucknow, UP, India after approval by ethical review board of the university. Written informed consent was obtained from all participants.

Study was conducted from October 2017 to July 2018, 50 randomly selected students of $1^{\text {st }}$ year MBBS and BDS, 2017 batch (30 males, 20 females) were evaluated. Participants in the study were free of CTS symptoms such as pain, numbness, burning sensation, itching or discomfort in hand, wrist, upper extremity or weakness in any area of the median nerve distribution. None of the volunteers received any medication that could alter sensory or motor functions or gave history of any injury or surgery of upper extremity. Certain physical tests were also additionally performed for exclusion.

Height, weight and wrist circumference were noted. Height of the subjects was measured without shoes on stadiometer in centimetres $(\mathrm{cm})$ with an accuracy of $0.1 \mathrm{~cm}$. Weight was measured (without shoes) on a weighing machine with an accuracy of 0.5 $\mathrm{Kg}$. Bilateral wrist circumference was noted at distal wrist crease by a measuring tape (in $\mathrm{cm}$ ).

Ultrasonography was performed on Esaote Europe My Lab $\mathbf{4 0}$ with linear probe of frequency range $6-13 \mathrm{MHz}$. Median nerve was identified using anatomical landmarks, and was studied at two predetermined sites, firstly in mid-forearm (mid-point between elbow crease and distal crease); and secondly at distal wrist crease. Nerve was identified on the basis of its appearance as dark punctuate areas (fascicular pattern) with hyperechoic margin (perineurium) [4] and differentiated from surrounding muscles which presented with hypoechoic pattern interspersed with small hyperechoic foci.

The ultrasound measurements were made by two separate examiners. Median nerve was identifiable at two pre-defined sites. CSA was measured by ellipse formula after excluding the hyperechoic epineurium, transverse axis (ML diameter) and anteroposterior axis (AP diameter) of median nerve was measured by distance method at both sites in all male and female subjects and flattening ratio was calculated (Fig. 1-4). 


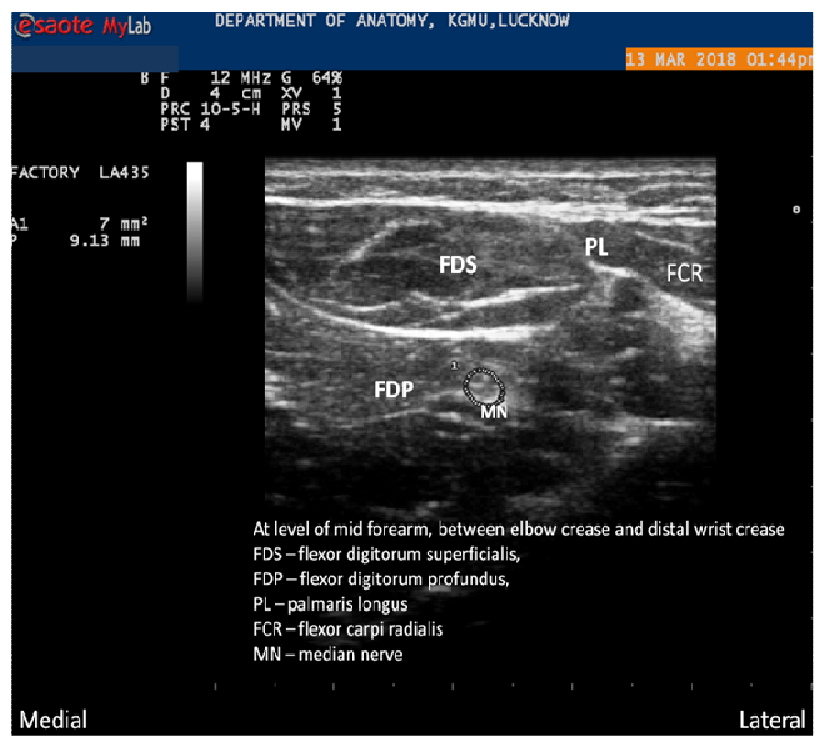

Fig. 1 A cross-sectional view of the median nerve at mid forearm showing CSA measurement by dotted line A 1 Cross sectional area, $\mathrm{P}$ perimeter

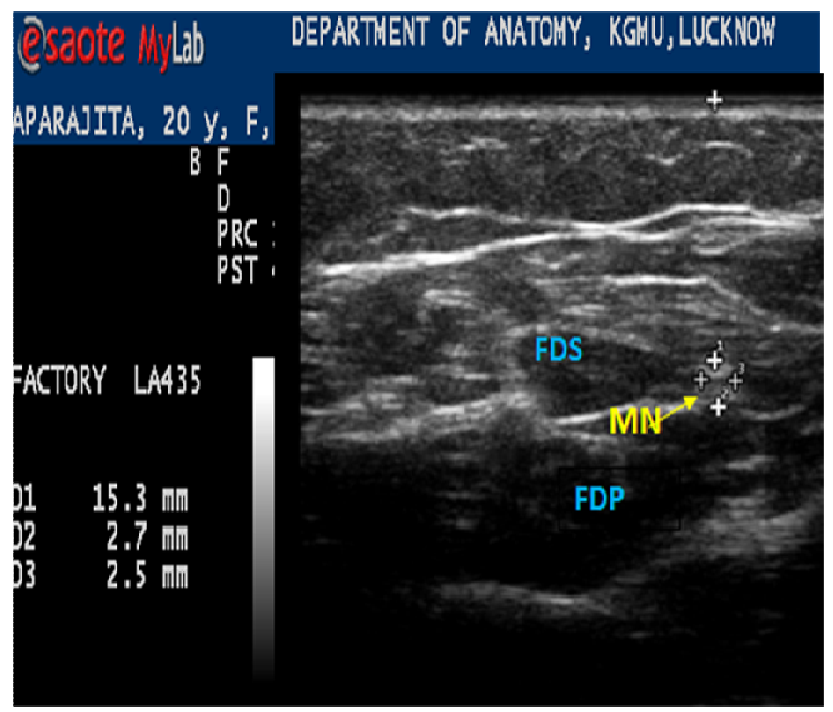

Fig. 2 Transverse scan of medial nerve at mid forearm showing measurements of major and minor axis

MN-median nerve, FDS-flexor digitorum profounds D1 depth from skin D2-major axis, D3-minor axis

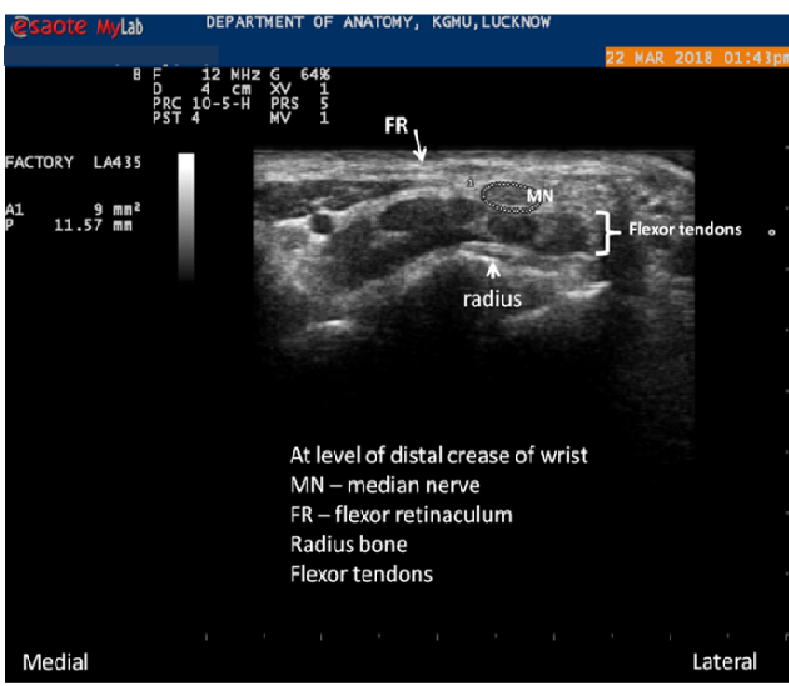

Fig. 3 Transverse scan at distal wrist crease showing mediannerve by dotted line, A1 is CSA and $P$ is perimeter.

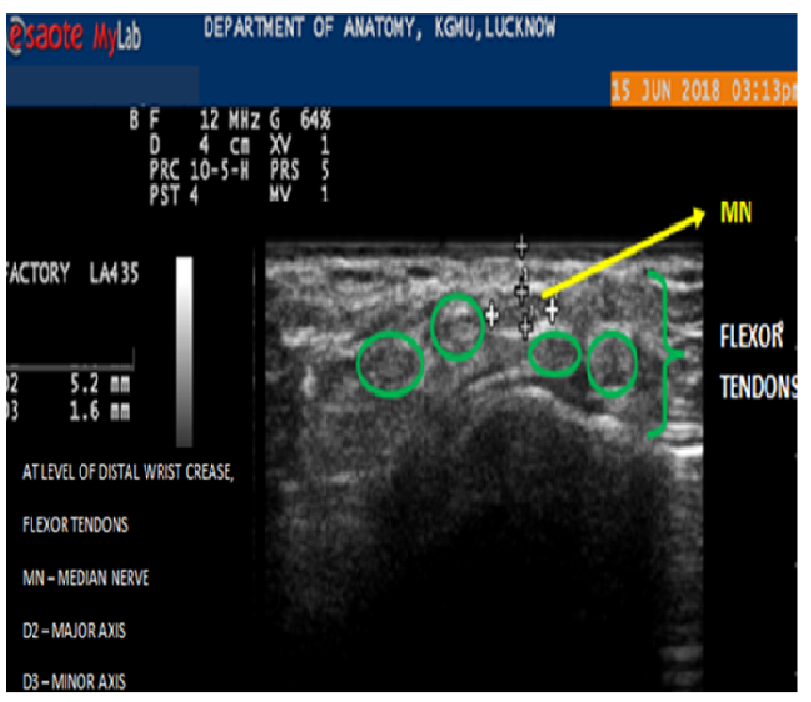

Fig. 4 Transverse scan at distal wrist crease showing median nerve major and minor axis measurement along with flexor tendons 
During examination, upper limb was kept flexed at elbow, supinated and with wrist in neutral position. Median nerve was localized and traced longitudinally from mid-forearm to the level of distal crease (just proximal to proximal border of flexor retinaculum). At the wrist, nerve was differentiated from tendons on the basis of sonographic architecture and movement of tendons that accompanied the joint movement [4]. Measurements were made on a transverse scan; CSA was measured by the ellipsoid technique (inside the hyperechoic epineurium) (Fig. 1\&3), transverse axis (ML diameter) and anteroposterior axis (AP diameter) of median nerve were measured by using distance method (Fig. 2 \&4). The transducer was placed perpendicular to avoid any obliquity during measurement and probe was placed gently to avoid distortion of nerve. Transverse and AP diameters were used to calculate flattening ratio (major axis/minor axis), that provided information about changes in median nerve morphology and served as an index of nerve compression. Measurements were taken bilaterally, observations were recorded, tabulated and statistically analysed.

\section{OBSERVATIONS AND RESULTS}

The study was conducted on 50 asymptomatic volunteers (undergraduate students) in the Ultrasound Laboratory of Department of Anatomy, KGMU. Basic parameters like height, weight, and wrist circumference were also recorded.

The age ranged from 18 to 22 years for males (20.28 \pm 2.83 years) and for females it was 18 to 21 years (19.75 \pm 1.28 years). For the entire sample, mean value for height- $166 \pm 8.71 \mathrm{cms}$; weight$63.24 \pm 11.03 \mathrm{kgs}$; and wrist circumference was $15.73 \pm 1.20 \mathrm{cms}$.

At mid-forearm (MFA), overall mean cross sectional area was similar for both right and left median nerves $\left(5.96 \pm 1.48 \mathrm{~mm}^{2} ; 5.96 \pm 1.43 \mathrm{~mm}^{2}\right)$. CSA increased distally: at distal crease of wrist (DCW), RMN CSA measured $7.4 \pm 1.68 \mathrm{~mm}^{2}$ and LMN CSA measured $7.54 \pm 1.67 \mathrm{~mm}^{2}$. At DCW mean CSA of LMN was larger than mean CSA of RMN (Table 1).
Table 1: Median nerve CSA at mid-forearm and distal crease of wrist

\begin{tabular}{|c|c|c|c|}
\hline Site & $\begin{array}{c}\text { Number of } \\
\text { extremities }\end{array}$ & $\begin{array}{c}\text { CSA RMN } \\
\left(\mathbf{m m}^{2}\right)\end{array}$ & $\begin{array}{c}\text { CSA LMN } \\
\left(\mathbf{m m}^{\mathbf{2}}\right)\end{array}$ \\
\hline Mid-forearm & 100 & $5.96 \pm 1.48$ & $5.96 \pm 1.43$ \\
\hline $\begin{array}{c}\text { Distal wrist } \\
\text { crease }\end{array}$ & 100 & $7.40 \pm 1.68$ & $7.54 \pm 1.67$ \\
\hline
\end{tabular}

In Females, mean CSA MFA of LMN $\left(5.85 \pm 1.39 \mathrm{~mm}^{2}\right)$ was greater than mean CSA MFA of RMN $\left(5.6 \pm 1.73 \mathrm{~mm}^{2}\right)$. CSA increased distally: at distal crease of wrist; CSA DCW RMN was $7.5 \pm 2.12 \mathrm{~mm}^{2}$ and CSA DCW for LMN was $7.55 \pm 1.39 \mathrm{~mm}^{2}$ (Table 2). Though CSA at both sites was greater on left, the overall increase in CSA (CSA DCW- CSA MFA) was greater on right than on left side; $1.9 \mathrm{~mm}^{2}$ (right) as compared to $1.7 \mathrm{~mm}^{2}$ (left); degree of increase was $33.93 \%$ on right as compared to $30.36 \%$ on the left (Table 2).

Table 2: Mean CSA of right and left median nerve in Females $(n=20)$

\begin{tabular}{|c|c|c|c|}
\hline Site & $\begin{array}{c}\text { Number of } \\
\text { extremities }\end{array}$ & $\begin{array}{c}\text { CSA RMN } \\
\left(\mathbf{m m}^{2}\right)\end{array}$ & $\begin{array}{c}\text { CSA LMN } \\
\left(\mathbf{m m}^{2}\right)\end{array}$ \\
\hline Mid-forearm & 40 & $5.6 \pm 1.73$ & $5.85 \pm 1.39$ \\
\hline $\begin{array}{c}\text { Distal wrist } \\
\text { crease }\end{array}$ & 40 & $7.5 \pm 2.12$ & $7.55 \pm 1.39$ \\
\hline
\end{tabular}

In males, at mid-forearm, mean CSA MFA of RMN $\left(6.2 \pm 1.27 \mathrm{~mm}^{2}\right)$ was greater than mean CSA MFA of LMN $\left(6.03 \pm 1.47 \mathrm{~mm}^{2}\right)$. CSA DCW RMN was $7.33 \pm 1.35 \mathrm{~mm}^{2}$ and CSA DCW LMN was $7.53 \pm 1.85$ $\mathrm{mm}^{2}$. In contrast to females the increase was comparatively greater on left side; $1.5 \mathrm{~mm}^{2}$ (left) as compared to $1.13 \mathrm{~mm}^{2}$ (right); degree of increase was $24.88 \%$ on the right and $18.23 \%$ on the left (Table 3).

Table 3: Mean CSA of right and left median nerves in Males $(n=30)$

\begin{tabular}{|l|c|c|c|}
\hline \multicolumn{1}{|c|}{ Site } & $\begin{array}{c}\text { Number of } \\
\text { extremities }\end{array}$ & $\begin{array}{c}\text { CSA RMN } \\
\left(\mathbf{m m}^{2}\right)\end{array}$ & $\begin{array}{c}\text { CSA LMN } \\
\left(\mathbf{m m}^{2}\right)\end{array}$ \\
\hline Mid-forearm & 60 & $6.2 \pm 1.27$ & $6.03 \pm 1.47$ \\
\hline Distal wrist crease & 60 & $7.33 \pm 1.35$ & $7.53 \pm 1.85$ \\
\hline
\end{tabular}

CSA MFA was greater in males as compared to females on both sides; the difference was greater on right side than left. CSA DCW was bilaterally greater in females as compared to males; the difference being greater on right side (Table 4). The degree of increase 
in CSA along its course from forearm to wrist was greater in females as compared to males (Table 4).

Table 4: Comparison of mean CSA of right and left median nerves among male and females

\begin{tabular}{|c|c|c|c|c|}
\hline \multirow{2}{*}{ Site } & \multicolumn{2}{|c|}{ Right } & \multicolumn{2}{c|}{ Left } \\
\cline { 2 - 5 } & $\begin{array}{c}\text { Male } \\
(\mathbf{n = 3 0 )}\end{array}$ & $\begin{array}{c}\text { Female } \\
(\mathbf{n = 2 0})\end{array}$ & $\begin{array}{c}\text { Male } \\
(\mathbf{n = 3 0 )}\end{array}$ & $\begin{array}{c}\text { Female } \\
(\mathbf{n = 2 0})\end{array}$ \\
\hline $\begin{array}{c}\text { Mid-Forearm } \\
\left.\text { CSA (mm } \mathbf{~}^{2}\right)\end{array}$ & $6.20 \pm 1.27$ & $5.60 \pm 1.73$ & $6.03 \pm 1.47$ & $5.85 \pm 1.39$ \\
\hline $\begin{array}{c}\text { Distal Wrist } \\
\text { Crease CSA } \\
\left.\mathbf{( m m}^{2}\right)\end{array}$ & $7.33 \pm 1.35$ & $7.50 \pm 2.12$ & $7.53 \pm 1.85$ & $7.55 \pm 1.39$ \\
\hline
\end{tabular}

At mid-forearm, MFA RMN ML diameter was $3.50 \pm 0.64 \mathrm{~mm}$ and $\mathrm{LMN} \mathrm{ML}$ diameter was $3.44 \pm 0.58 \mathrm{~mm}$. MFA AP diameter of RMN was $2.09 \pm 0.34$ almost equivalent to AP diameter of LMN which was 2.10 \pm 0.27 . At distal wrist crease, DCW ML diameter of RMN was $5.10 \pm 0.99$ and for $L M N$ was $4.94 \pm 0.92$. DCW AP diameter of RMN was $1.73 \pm 0.38$ and for LMN was $1.84 \pm 0.48$. Therefore, the nerves were more flattened oval in shape on right than left side. The observations were indicative of greater alteration in shape of nerve on the right side than left (Table 5).

Table 5: Overall mean value of major and minor axis on cross-section of median nerve

\begin{tabular}{|c|c|c|c|c|}
\hline \multirow{2}{*}{ Site } & \multicolumn{2}{|c|}{ Right } & \multicolumn{2}{c|}{ Left } \\
\cline { 2 - 5 } & $\begin{array}{c}\text { Major axis } \\
(\mathbf{m m})\end{array}$ & $\begin{array}{c}\text { Minor axis } \\
(\mathbf{m m})\end{array}$ & $\begin{array}{c}\text { Major axis } \\
(\mathbf{m m})\end{array}$ & $\begin{array}{c}\text { Minor axis } \\
(\mathbf{m m})\end{array}$ \\
\hline $\begin{array}{c}\text { Mid- } \\
\text { forearm }\end{array}$ & $3.50 \pm 0.64$ & $2.09 \pm 0.34$ & $3.44 \pm 0.58$ & $2.10 \pm 0.27$ \\
\hline $\begin{array}{c}\text { Distal } \\
\text { crease }\end{array}$ & $5.10 \pm 0.99$ & $1.73 \pm 0.38$ & $4.94 \pm 0.92$ & $1.84 \pm 0.48$ \\
\hline
\end{tabular}

Flattening ratio (FR) was calculated as a ratio between the major axis and minor axis. MFA FR of RMN was $1.71 \pm 0.45$ and MFA FR of LMN was $1.66 \pm 0.33$. DCW FR of RMN was $3.08 \pm 0.92$ and DCW FR of LMN was $2.78 \pm 0.66$. Hence, at mid-forearm, left median nerve was rounder as compared to right median nerve; at the wrist right median nerve was transversely more oval as compared to left median nerve. Right median nerve displayed greater flattening at distal crease than left median nerve (Table 6).
Table 6: Overall mean values of flattening ratio of median nerve at mid-forearm and distal wrist crease

\begin{tabular}{|c|c|c|}
\hline \multirow{2}{*}{ Site } & \multicolumn{2}{|c|}{ Flattening Ratio } \\
\cline { 2 - 3 } & RMN & LMN \\
\hline Mid-forearm & $1.71 \pm 0.45$ & $1.66 \pm 0.33$ \\
\hline Distal crease & $3.08 \pm 0.92$ & $2.78 \pm 0.66$ \\
\hline
\end{tabular}

Among the 20 female subjects, at mid-forearm, MFA ML diameter of RMN was $3.46 \pm 0.59$ and of LMN was $3.36 \pm 0.48$ whereas MFA AP diameter of RMN was $2.03 \pm 0.34$ and of $L M N$ was $2.06 \pm 0.25$. At distal wrist crease, DCW ML diameter of RMN was $5.33 \pm 1.00$ and of $L M N$ was $5.14 \pm 0.86$ whereas DCW AP diameter of RMN was $1.67 \pm 0.31$ and of LMN was $1.93 \pm 0.63$. Observations revealed that at mid-forearm right nerve was wider and thinner as compared to left nerve (RMN-3.46 $\pm 0.59 \mathrm{~mm}$; LMN-3.36 $\pm 0.48 \mathrm{~mm})$. The increase in major axis from mid forearm to distal wrist crease indicated a change in shape from round at forearm to a transverse oval at the distal wrist crease. Increase in transverse axis of nerve along its course from MFA to DCW was $54.05 \%$ on the right side as compared to $52.98 \%$ on the left (Table 7 ).

Table 7: Right versus left limb major axis \& minor axis of median nerve cross-section in females

\begin{tabular}{|c|c|c|c|c|c|}
\hline Site & \multirow[b]{2}{*}{$\begin{array}{l}\text { Number } \\
\text { of limbs }\end{array}$} & \multicolumn{2}{|c|}{ Right } & \multicolumn{2}{|c|}{ Left } \\
\hline & & $\begin{array}{c}\text { Major } \\
\text { axis } \\
(\mathrm{mm})\end{array}$ & $\begin{array}{l}\text { Minor } \\
\text { axis } \\
(\mathrm{mm})\end{array}$ & $\begin{array}{l}\text { Major } \\
\text { axis } \\
(\mathrm{mm})\end{array}$ & $\begin{array}{c}\text { Minor } \\
\text { axis } \\
(\mathrm{mm})\end{array}$ \\
\hline $\begin{array}{l}\text { Mid- } \\
\text { forearm }\end{array}$ & 40 & $\begin{array}{c}3.46 \pm \\
0.59\end{array}$ & $\begin{array}{c}2.03 \pm \\
0.34\end{array}$ & $\begin{array}{c}3.36 \pm \\
0.48\end{array}$ & $\begin{array}{c}2.06 \pm \\
0.25\end{array}$ \\
\hline $\begin{array}{c}\text { Distal } \\
\text { crease }\end{array}$ & 40 & $\begin{array}{r}5.33 \\
\pm 1.00\end{array}$ & $\begin{array}{c}1.67 \pm \\
0.31\end{array}$ & $\begin{array}{c}5.14 \pm \\
0.86\end{array}$ & $\begin{array}{c}1.93 \pm \\
0.63\end{array}$ \\
\hline
\end{tabular}

At mid-forearm, MFA FR of RMN was $1.77 \pm 0.57$ and of LMN was $1.65 \pm 0.28$. Evident flattening of nerves was documented as the nerve approached the distal crease of wrist. At distal crease of wrist, DCW FR of RMN was $3.30 \pm 0.91$ and of $L M N$ was $2.83 \pm 0.74$. At MFA LMN (1.65 \pm 0.28$)$ was rounder than RMN $(1.77 \pm 0.57)$. Nerves flattened on both sides as they approached the distal wrist crease (DCW RMN $3.30 \pm 0.91$; DCW LMN 2.83 \pm 0.74 ); the overall flattening observed in the right median nerve (DCW RMN FR - MFA RMN FR= 1.5) was more than left median nerve (DCW LMN FR - MFA LMN FR=1.18) (Table 8). 
Sonographic study on median nerve......

Table 8: Mean value of flattening ratio of median nerve in females

\begin{tabular}{|c|c|c|}
\hline Site & Right & Left \\
\hline \multirow{2}{*}{ Mid-forearm } & Flattening ratio & Flattening ratio \\
\cline { 2 - 3 } & $1.77 \pm 0.57$ & $1.65 \pm 0.28$ \\
\hline Distal crease & $3.30 \pm 0.91$ & $2.83 \pm 0.74$ \\
\hline
\end{tabular}

In males at mid-forearm, MFA RMN ML diameter was $3.50 \pm 0.64$ and $L M N$ ML diameter was $3.44 \pm 0.58$ whereas MFA RMN AP diameter was $2.09 \pm 0.34$ and of LMN AP diameter was $2.10 \pm 0.27$. At distal wrist crease, DCW RMN ML diameter was $4.96 \pm 0.97$ and LMN ML diameter was $4.81 \pm 0.95$ whereas DCW AP diameter of RMN was $1.77 \pm 0.43$ and LMN AP diameter was $1.79 \pm 0.35$. There was an increase in major axis from mid forearm $(3.50 \pm 0.64)$ to distal crease $(4.96 \pm 0.97)$ on the right side and also on left side $(3.44 \pm 0.58 \mathrm{~mm}$ to $4.81 \pm 0.95)$. This was accompanied by a reduction in the minor axis from $2.09 \pm 0.34$ to $1.77 \pm 0.43$ on the right and from $2.10 \pm 0.27$ to $1.79 \pm 0.35$ on the left side. On both sides nerves elongated transversely, increase in transverse axis was $41.71 \%$ on the right and $39.83 \%$ on the left (Table 9).

Table 9: Right versus left limb major axis \& minor axis of median nerve cross-section in males

\begin{tabular}{|c|c|c|c|c|c|}
\hline Site & \multirow{2}{*}{$\begin{array}{l}\text { Number } \\
\text { of limbs } \\
\text { examined }\end{array}$} & \multicolumn{2}{|c|}{ Right } & \multicolumn{2}{|c|}{ Left } \\
\hline & & $\begin{array}{l}\text { Major } \\
\text { axis } \\
(\mathrm{mm})\end{array}$ & $\begin{array}{l}\text { Minor } \\
\text { axis } \\
(\mathrm{mm})\end{array}$ & $\begin{array}{c}\text { Major } \\
\text { axis } \\
(\mathrm{mm})\end{array}$ & $\begin{array}{l}\text { Minor } \\
\text { axis } \\
(\mathrm{mm})\end{array}$ \\
\hline Mid-forearm & 60 & $\begin{array}{c}3.50 \pm \\
0.64\end{array}$ & $\begin{array}{c}2.09 \pm \\
0.34\end{array}$ & $\begin{array}{c}3.44 \pm \\
0.58\end{array}$ & $\begin{array}{c}2.10 \pm \\
0.27\end{array}$ \\
\hline Distal crease & 60 & $\begin{array}{c}4.96 \pm \\
0.97\end{array}$ & $\begin{array}{c}1.77 \pm \\
0.43\end{array}$ & $\begin{array}{c}4.81 \pm \\
0.95\end{array}$ & $\begin{array}{c}1.79 \pm \\
0.35\end{array}$ \\
\hline
\end{tabular}

At mid-forearm, MFA FR of RMN was $1.68 \pm 0.36$ and of LMN was $1.67 \pm 0.36$. At distal crease of wrist, DCW FR of RMN was $2.94 \pm 0.91$ and of LMN was $2.74 \pm 0.61$. It was observed that the nerve was rounder in forearm with a flattening ratio that was almost similar on right $(1.68 \pm 0.36)$ and left $(1.67 \pm 0.36)$ sides. Flattening of nerves were observed on both sides as they come closer to distal wrist crease (DCW RMN $2.94 \pm 0.91$; DCW LMN 2.74 \pm 0.61 ); the overall flattening observed in right median nerve (DCW RMN FR - MFA RMN FR $=1.26$ ) was more than left median nerve (DCW LMN FR - MFA LMN FR = 1.07) (Table 10).
Table 10: Mean value of flattening ratio of median nerve in males

\begin{tabular}{|l|c|c|}
\hline \multirow{2}{*}{ Site } & \multicolumn{2}{|c|}{ Flattening Ratio } \\
\hline \multirow{2}{*}{ Mid-forearm } & Right & Left \\
\cline { 2 - 3 } & $1.68 \pm 0.36$ & $1.67 \pm 0.36$ \\
\hline Distal crease & $2.94 \pm 0.91$ & $2.74 \pm 0.61$ \\
\hline
\end{tabular}

For right median nerve, the mean value of RMN DCW was found to be $7.4 \pm 1.68$ and RMN MFA was $5.96 \pm 1.48$. The WFR RMN calculated was $1.30 \pm 0.38$. For left median nerve, the mean value of LMN DCW was observed to be $7.54 \pm 1.67$ and LMN MFA was 5.96 \pm 1.43 . The WFR LMN calculated was $1.31 \pm 0.34$ (Table 11).

Table 11: Overall mean value of wrist-to-forearm ratio (WFR) of median nerve $(n=50)$

\begin{tabular}{|c|c|c|c|}
\hline DCW/ MFA & WFR (RMN) & DCW/ MFA & WFR (LMN) \\
\hline $7.4 \pm 1.68 /$ & $1.30 \pm 0.38$ & $7.54 \pm 1.67 /$ & $1.31 \pm 0.34$ \\
$5.96 \pm 1.48$ & & $5.96 \pm 1.43$ & \\
\hline
\end{tabular}

In females $(n=20)$, for right median nerve, the mean value of RMN DCW was $7.5 \pm 2.12$ and $R M N$ MFA was $5.6 \pm 1.73$; the RMN WFR calculated was $1.42 \pm 0.49$. For left median nerve, the mean value of LMN DCW was found to be $7.55 \pm 1.39$ and LMN MFA was $5.85 \pm 1.39$; the LMN WFR evaluated was $1.34 \pm 0.33$ (Table 12).

Table 12: Mean value of wrist-to-forearm ratio (WFR) of median nerve in females

\begin{tabular}{|c|c|c|c|}
\hline \multicolumn{2}{|c|}{ RMN } & \multicolumn{2}{c|}{ LMN } \\
\hline DCW/ MFA & WFR & DCW/ MFA & WFR \\
\hline $7.5 \pm 2.12 /$ & $1.42 \pm 0.49$ & $7.55 \pm 1.39 /$ & $1.34 \pm 0.33$ \\
$5.6 \pm 1.73$ & & $5.85 \pm 1.39$ & \\
\hline
\end{tabular}

In males $(n=30)$, for right median nerve, the mean value of RMN DCW was observed to be $7.33 \pm 2.75$ and RMN MFA was 6.20 \pm 2.53 ; the calculated RMN WFR was $1.21 \pm 1.12$. For left median nerve, the mean value of LMN DCW was seen as $7.53 \pm 2.79$ and $L M N$ MFA was $6.03 \pm 2.50$; the calculated LMN WFR was $1.29 \pm 1.15$ (Table 13). 
Table 13: Mean value of wrist-to-forearm ratio (WFR) of median nerve in males

\begin{tabular}{|c|c|c|c|}
\hline \multicolumn{2}{|c|}{ RMN } & \multicolumn{2}{c|}{ LMN } \\
\hline DCW/ MFA & WFR & DCW/ MFA & WFR \\
\hline $7.33 \pm 2.75 /$ & $1.21 \pm 1.12$ & $7.53 \pm 2.79 /$ & $1.29 \pm 1.15$ \\
$6.20 \pm 2.53$ & & $6.03 \pm 2.50$ & \\
\hline
\end{tabular}

\section{DISCUSSION}

The carpal tunnel houses the median nerve along with the long flexor tendons. Any compression of the median nerve in the tunnel causing its entrapment results in carpal tunnel syndrome presenting with sensory and motor deficit along its distribution. Prevalence of CTS in the general population is $9.2 \%$ in women and $6 \%$ in men [6]. Patient's symptoms and positive testing helps to identify the cases. Till date electrophysiological study is an essential step in establishing the diagnosis. In forthcoming years, highresolution ultrasonography shall enroute the clinical diagnosis of CTS. For assessment of CTS, highresolution ultrasonography should become a complementary technique in addition to nerve conduction study.

Ultrasound is considered important for peripheral nerve evaluation and CTS diagnosis; it is fast and comfortable for patients. Furthermore, US can be used to not only diagnose CTS but also to detect underlying causal anatomical abnormalities. The measurement of CSA is the most-studied method for the diagnosis of CTS [7]. In the year 2004, Yesildag et al. (2004) documented that CSA of median nerve at the inlet level of the carpal tunnel has a sensitivity of $89 \%$ and specificity of $94.7 \%$ when the cut-off was set to 10.5 $\mathrm{mm}$. These findings were studied on 86 patients with symptomatic CTS and 45 asymptomatic individuals [8]. Cartwright et al. (2009) studied 50 individuals (100 arms; 32 females, 18 males) for ultrasonographic reference values of normal median nerve. Median nerve CSA $\left(\mathrm{mm}^{2}\right)$ at distal wrist crease was $9.8 \mathrm{~mm}^{2}$ and mid-forearm was $7.5 \mathrm{~mm}^{2}$. The mean side-to-side difference was $1.2 \mathrm{~mm}^{2}$ [9]. Claes et al. (2010) studied 54 healthy control subjects ( 25 male and 29 female; mean age 41 years). Out of 98 wrists (52 right and 46 left- handed) that were finally accounted for CSA of median nerve was measured ultrasonographically, at the inlet of carpal tunnel (distal wrist crease was used as an external landmark). The mean CSA of right median nerve in males $(n=25)$ and females $(n=27)$ was found to be $10.2 \mathrm{~mm}^{2}$ and $8.4 \mathrm{~mm}^{2}$, respectively. The mean CSA of left median nerve for males $(n=23)$ and females $(n=23)$ was found to be $10.0 \mathrm{~mm}^{2}$ and $8.0 \mathrm{~mm}^{2}$, respectively [10]. Ulaşli et al. (2013) measured CSA at three levels of the carpal tunnel and suggested that a maximum CSA of $>10 \mathrm{~mm}^{2}$ is more sensitive for the US diagnosis of CTS. Among 95 wrists of 55 patients of CTS, CSA at carpal tunnel inlet was found to be $13.0 \pm 3.14 \mathrm{~mm}^{2}$ where as among 27 volunteers (48 wrists) CSA of median nerve was $8.98 \pm 1.83 \mathrm{~mm}^{2}$ [11].

We studied median nerve CSA at two sites, mid forearm and distal wrist crease. At mid-forearm, overall mean cross sectional area was similar for both right and left median nerves $\left(5.96 \pm 1.48 \mathrm{~mm}^{2} ; \quad 5.96\right.$ $\pm 1.43 \mathrm{~mm}^{2}$ ). At mid-forearm, the mean value of median nerve CSA was in confirmation with Martinoli et al. (2002), Tagliafico et al. (2013) and Sugimoto et al. (2013) [12-14]. But, contrastingly in a study by Bathala et al. (2014), in Asian population, the mean values showed smaller CSA of median nerve [3]. In the present study, at distal crease of wrist, there is comprehensive increase in CSA of RMN and LMN and it measured $7.4 \pm 1.68 \mathrm{~mm}^{2}$ and $7.54 \pm 1.67 \mathrm{~mm}^{2}$, respectively. Mean CSA of left median nerve was larger than mean CSA of right median nerve. The mean CSA of right median nerve in males $(n=30)$ and females $(n=20)$ was observed to be $7.33 \pm 1.35 \mathrm{~mm}^{2}$ and $7.50 \pm 2.12 \mathrm{~mm}^{2}$, respectively. The mean CSA of left median nerve for males $(n=30)$ and females $(n=20)$ was noted to be $7.53 \pm 1.85 \mathrm{~mm}^{2}$ and $7.55 \pm 1.39 \mathrm{~mm}^{2}$, respectively.

Tai et al. (2012) systematically reviewed 28 articles on diagnostic test accuracy by ultrasonography for CTS. The cut-off values $\left(8-14 \mathrm{~mm}^{2}\right)$ provided in each article included were scrutinised for diagnostic accuracy. With cut-off value of $8 \mathrm{~mm}^{2}$ there was increase in sensitivity (94.3\%), while the cut-off value increased to $14 \mathrm{~mm}^{2}$, the specificity was highest $(96.5 \%)$. In these articles, there was proposal for cutoff value to be within range of $9-11 \mathrm{~mm}^{2}$. Authors proposed that CSA of median nerve at the inlet of carpal tunnel proved to be prime diagnostic criteria and the minimum value of $9 \mathrm{~mm}^{2}$ should be considered for diagnostic accuracy [15].

Wrist to forearm ratio is also a recommended measurement; however, authors differ in their views regarding its superiority over CSA, certain studies report that the wrist-to-forearm ratio was superior [16], whereas others contrarily believe it is not so [17]. Hobson-Webb et al. (2008) indicated that a wrist-toforearm ratio $\geq 1.4$ gave $100 \%$ sensitivity for diagnosing CTS, while using only the median nerve area at the wrist resulted in a sensitivity of $45-93 \%$ 
[16]. Lange (2013) indicated that the optimal cut-off value for the wrist-to-forearm ratio for CTS was 1.6 [18]. The range for WFR for RMN was 1.18-1.33, and for LMN was 1.14-1.29. In the present study, the mean WFR for RMN was 1.24 and LMN 1.26 and in conformation to the values reported in previous studies. Hence, the findings are in acceptance with the view of taking WFR $\geq 1.4$ as cut off in diagnosing CTS.

Bueno-Gracia et al. (2017) defined major and minor axis measurements that provided an indication of nerve's rounded structure. The ratio between these two parameters reaching value to 1 specifies a circle [19]. There is alteration in the morphology of nerve as it courses through the arm, forearm, wrist and carpal tunnel. Median nerve appears to be rounded while traversing through arm and mid-forearm and it undergoes an obligatory alteration in morphology as it approaches the carpal tunnel; where it was observed to acquire an elliptical configuration. Flattening ratio (major axis/ minor axis) has been proposed for establishing diagnosis of CTS. In the present study, at mid-forearm, mean FR of RMN was $1.71 \pm 0.45$ and of LMN $1.66 \pm 0.33$ depicted left median nerve to be rounder as compared to right. At distal wrist crease, comparison of mean FR of LMN $(2.78 \pm 0.66)$ and RMN $(3.08 \pm 0.92)$ indicated that the right median nerve was more flattened than the left nerve. Our findings for right median nerve were in conformation to that of Buchberger et al. (1991), and Duncan et al (1999), $[20,21]$ whereas left median nerve observations were in conformation to the study by Nakamichi and Tachibana (2000) and Abe (2004) [22,23]. The values of major axis of right median nerve at distal crease in our study was in conjunction with Bueno-Gracia et al. (2017) and Nakamichi and Tachibana (2000) [19,22]. The study revealed major axis of left median nerve at distal crease, was higher than the value given by Abe (2004) and McCartney et al. (2007) [23,24]. The minor axis measured in the study population showed a lower value than that of Nakamichi and Tachibana (2000) [22].

In all our asymptomatic individuals of Indian population $(n=50)$, the calculated cut-off values of CSA of RMN is $8.92 \mathrm{~mm}^{2}$ at mid-forearm and $10.76 \mathrm{~mm}^{2}$ at distal wrist crease. The calculated cut-off value of CSA of LMN is $8.82 \mathrm{~mm}^{2}$ at mid-forearm and $10.88 \mathrm{~mm}^{2}$ at distal wrist crease. In females, the evaluated cut-off value of CSA for RMN is $9.06 \mathrm{~mm}^{2}$ at mid-forearm and $11.74 \mathrm{~mm}^{2}$ at distal wrist crease and for LMN, $8.63 \mathrm{~mm}^{2}$ at mid-forearm and $10.33 \mathrm{~mm}^{2}$ at distal wrist crease. In males, the computed cut-off value of CSA for RMN is $8.74 \mathrm{~mm}^{2}$ at mid-forearm and $10.03 \mathrm{~mm}^{2}$ at distal wrist crease whereas for LMN is $8.97 \mathrm{~mm}^{2}$ at mid-forearm and $11.23 \mathrm{~mm}^{2}$ at distal wrist crease.

We also additionally observed that in female subjects, the increment in cross sectional area at wrist was $33.94 \%$ on the right as compared to $30.96 \%$ on the left. In comparison to this, the increment in cross sectional area at wrist was much lesser in males; it was $24.88 \%$ on the right and $18.23 \%$ on the left. On meticulous search for literature, we were not able to find any literature regarding increase in cross-sectional area or transverse axis at wrist for both sexes for any comparison.

The study described the normal CSAs of median nerve at mid forearm and distal wrist crease. As seen in our observations the CSA at distal crease was greater bilaterally in females as compared to male subjects. The increase in CSA as well as transverse axis was of a much greater degree than in males. This could be due to work related increased movements of flexion and extension at wrist (increasing the compressive forces in carpal tunnel) in females in contrast to male subjects.

It was seen that the nerve was round in morphology in the forearm and flattened on approaching the carpal tunnel. This obligatory alteration is related to passage of nerve through the confines of carpal tunnel in a restricted area. Changes in morphology of the nerve proximal to the inlet of tunnel are seen in asymptomatic normal nerves and are not necessarily part of nerve pathology. Exaggerations in these alterations define pathological changes and to differentiate this normal deviation in morphologic anatomy from pathology cut off values of flattening ratio and wrist forearm ratio can be helpful.

We compared our observations with previously defined cut-offs for abnormal nerves and our findings were in accordance, and within normal limits.

\section{CONCLUSION}

We conclude that median nerve morphology can be assessed ultrasonographically at mid-forearm and distal wrist crease and measurements can be taken. The morphology of nerve undergoes a normal alteration which is within clearly defined limits set by cut off values. Median nerve shape alters from minimally oval in forearm to obviously oval at distal wrist crease. Despite changes in morphology and morphometry the values remained within normal limits, hence the changes in morphometry were normal and 
obligatory. Increase in flattening ratio confirmed that nerve displayed obvious flattening on reaching distal crease. A careful observation of the degree of changes in size and shape helps in differentiating normal phenomenon from compressive distortion.

Nerve CSA, Flattening ratio and Wrist forearm ratio of median nerve are the parameters which could be useful in assessing CTS. Side to side differences between RMN and LMN CSA $<1 \mathrm{~mm}^{2}$ meant that nerve of either side could serve as a control during morphometry. Exaggeration of these morphological changes accompanies nerve pathologies. The degree of changes differs among males and females. We would like to propose that instead of having any common cut off, the percent change in CSA and transverse axis at the wrist, on individual basis is more relevant. Also comparison of this change between symptomatic and asymptomatic sites of the same individual, with the normal side serving as control, could be more informative and diagnostic.

\section{REFERENCES}

1. Standring S. Gray's Anatomy-- The anatomical basis of clinical practice. Churchill Livingstone: Elsevier, $39^{\text {th }}$ ed., 2004; $857-$ 932.

2. Wertsch JJ, Melvin J. Median nerve anatomy and entrapment syndromes: a review. Arch Phys Med Rehabil. 1982; 63 (12):623-7.

3. Bathala L, Kumar P, Kumar K, Shaik AB. Normal values of median nerve cross-sectional area obtained by ultrasound along its course in the arm with electrophysiological correlations, in 100 Asian subjects. Muscle Nerve. 2014; 49 (2):284-286.

4. Suk JI, Walker FO, Cartwright MS. Ultrasound of peripheral nerves. Curr Neurol Neurosci Rep. 2013; 13(2): 328.

5. Buchberger W, Schön G, Strasser K, Jungwirth W. High resolution ultrasonography of the carpal tunnel. J Ultrasound Med. 1991; 10 (10): 531-537.

6. Alfonso C, Jann S, Massa R, Torreggiani A. Diagnosis, treatment and follow-up of the carpal tunnel syndrome: a review. Neurol Sci. 2010; 31 (3): 243-252.

7. Buchberger W, Judmaier W, Birbamer G, Lener M, Schmidauer C. Carpal tunnel syndrome: diagnosis with high-resolution sonography. Am J Roentgenol.1992; 159 (4): 793-798.

8. Yesildag A, Kutluhan S, Sengul N, Koyuncuoglu HR, Oyar O, Guler K, Gulsov UK. The role of ultrasonographic measurements of the median nerve in the diagnosis of carpal tunnel syndrome. Clin Radiol. 2004; 59 (10): 910-915.

9. Cartwright MS, Shin HW, Passmore LV, Walker FO. Ultrasonographic reference values for assessing the normal median nerve in adults. J Neuroimaging 2009; 19 (1):47-51.
10. Claes F, Meulstee J, Classen-Oude, Luttikhuis TT, Huygen PL, Verhagen WI. Usefulness of additional measurements of the median nerve with ultrasonography. . Neurol Sci. 2010; 31: 721-725.

11. Ulaşli AM, Duymuş $M$, Nacir B, Rana Erdem H, Koşar U. Reasons for using swelling ratio in sonographic diagnosis of carpal tunnel syndrome and a reliable method for its calculation. Muscle Nerve. 2013; 47 (3): 396-402.

12. Martinoli $C$, Schenone A, Bianchi S, Mandich $P$, Caponetto $C$, Abbruzzese M, Derch LE. Sonography of the median nerve in Charcot-Marie Tooth disease. Am J Roentgenol. 2002; 178 (6):1553-1556.

13. Tagliafico A, Martinoli C. Reliability of side-to-side sonographic cross-sectional area measurements of upper extremity nerves in healthy volunteers. Ultrasound Med. 2013; 32 (3):457-462.

14. Sugimoto $\mathrm{T}$, Oci $\mathrm{K}$, Hosomi N, Mukai T, Ueno H, Takahashi T. Ultrasonographic reference sizes of the median and ulnar nerves and the cervical nerve roots in healthy Japanese adults. Ultrasound Med Biol. 2013; 39 (9): 1560-1570.

15. Tai TW, Wu CY, Su FC, Chern TC, Jou IM. Ultrasonography for diagnosing carpal tunnel syndrome: A meta-analysis of diagnostic test accuracy. Ultrasound Med Biol. 2012; 38 (7):1121-1128.

16. Hobson-Webb LD, Massey JM, Juel VC, Sanders DB. The ultrasonographic wrist-to-forearm median nerve area ratio in carpal tunnel syndrome. Clin Neurophysiol. 2008; 119 (6): 1353-1357.

17. Visser LH, Smidt MH, Lee ML. Diagnostic value of wrist median nerve cross sectional area versus wrist-to-forearm ratio in carpal tunnel syndrome. Clin Neurophysiol. 2008; 119: 28982899.

18. Lange J. Carpal tunnel syndrome diagnosed using ultrasound as a first-line exam by the surgeon. J Hand Surg Eur Vol. 2013; 38 (6):627-632.

19. Bueno-Gracia E, Malo-Urries M, Ruiz-de-Escudero-Zapico A, Rodriguez-Marco S, Jimenez-del-Barrio S, Shacklok M et al. Musculoskeletal Science and Practice. 2017; 32: 17-22.

20. Buchberger W, Schon G, Strasser K, Jungwirth W. High resolution ultrasonography of the carpal tunnel. J Ultrasound Med. 1991; 10 (10): 531-537.

21. Duncan I, Sullivan $P$, Lomas F. Sonography in the diagnosis of carpal tunnel syndrome. AJR Am J Roentgenol. 1999; 173 (3): 681-684.

22. Nakamichi $\mathrm{K}$, Tachibana $\mathrm{S}$. Enlarged median nerve in idiopathic carpal tunnel syndrome. Muscle Nerve. 2000; 23 (11): 1713-1718.

23. Abe MJ. Ultrasound measurement of the median nerve for carpal tunnel syndrome of the non-handicapped and the handicapped. Phys Ther Sci. 2004; 16 (2): 107-114.

24. McCartney CJL, Daquan X, Constantinescue C, Abbas S, Chan VWS. Ultrasound examination of peripheral nerves in the forearm. Reg Anesth Pain Med. 2007; 32: 434-439. 